\title{
SIN NOMBRE, BABEL, AND THE CONFLICTS IN CONTACT ZONES
}

\author{
George Alexandre Ayres de Menezes Mousinho ${ }^{1 \times}$ \\ ${ }^{1}$ Universidade Federal de Santa Catarina, Florianópolis, SC, Brasil
}

\begin{abstract}
Contact zones can be understood as spaces where cultures meet and establish relations of power based on historical processes of domination and inequality. In such spaces and under such circumstances, power dynamics are sometimes resulted from the act of geographic dislocation, executed either by the individual from a central culture who is seen as the tourist or expatriate, or by the subaltern subject who travels to an imperialist nation in search of better prospects, who is seen as the sometimes illegal - immigrant. The objective of this article is to examine Sin Nombre (2009) and Babel (2006), two films that bring representations of both instances of transit and the inequity of power, through the lens of the postcolonial concept of contact zones.

Keywords: Immigration; contact zones; postcolonialism; Babel; Sin Nombre
\end{abstract}

\footnotetext{
"Professor at the Departamento de Língua e Literatura Estrangeiras from Universidade Federal de Santa Catarina. His current research involves the study of eschatological and post-apocalyptic literary and audiovisual narratives in science fiction. Academic interests include film theory, science fiction, adaptation studies, Gothic fiction, cultural studies, among other fields. E-mail: ayresmousinho@gmail.com. ORCID: https://orcid. org/0000-0001-6947-6451.
} 


\section{Introduction}

Narratives that reimagine travelling and migration often portray and/or focus on cultural and linguistic conflicts, relations of power and underlying subjugation, as well as issues of individual or collective restriction or violence. Whether such narratives reflect situations of mutual hostility - i.e. armed conflicts - or unequal power relations - i.e. cultural and economic challenges faced by illegal immigrants while settling down in a more economically and politically powerful country -, they simulate the intricacies of cultural disparity and the traces of colonial power that still reverberate in geopolitics. Some of these conflicts take place on territorial fringes, and are stimulated by transit and subsequent contact between different - sometimes neighbouring - cultures.

But the many and diverse instances of dislocation suggest pertinent questions about the relations of power involved in their differences; and those differences are fundamental to understanding the two portrayals that will be examined in this study. James Clifford (1992) states that "The traveler, by definition, is someone who has the security and privilege to move about in relatively unconstrained ways," and that some narratives do shed light on the freedom to visit and take advantage of a national territory by individuals of economically developed nations in contemporary contexts (107). The individual - or group - sets out to stay, permanently or temporarily, in a poorer and geopolitically less powerful country, for reasons that range from tourism to voluntary service to expatriation or exile. During their stay, they somehow cause changes in the local social order, which may include gentrification, commoditisation of local cultural elements - e.g., cuisine and art - and marginalization of sexualized bodies through touristic prostitution. However, the "relatively unconstrained" movements of that kind of traveller "do not offer any simple equivalence with other immigrant and migrant laborers" (Clifford 107). Hence the individual from a peripheral culture who journeys past borders but usually has no significant autonomy to move about, forced to become geographically isolated either through economic disenfranchisement or through a certain status of illegality in his/her stay. His/her dislocation is often one of pressure and coercion, and this other kind of dislocation is that of "poor, usually non-white, people who must leave home in order to survive" (Clifford 107).

Such uneven manifestations of power structures between central and peripheral nations arise from colonial processes historically stemming from commercial trade in the Atlantic in the $16^{\text {th }}$ century. The violence and exploitation of indigenous populations in both the Americas and Africa culminated in the rapid escalation of imperialism and capitalism, subjecting local populations to vicious dislocation. Dislocation is thus paramount to understanding the development and shifts of colonial structures from the Atlantic explorations to contemporaneity. Consequently, as suggested by Mary Louise Pratt (2008), "coloniality or what is the same, the colonial matrix of power," still extant due to the ascension of globalisation and modern imperialism ${ }^{1}$ ("In the Neocolony" 262); and boosted by the modern capitalist imperialism of the United States 
and Europe, creates patterns of cultural contact between the dominant and the Other (Mignolo and Tlostanova 2008, 109). Such a "colonial matrix of power explains the specificity of the modern/colonial world and the imperial/colonial expansion of Christian, Western, and Capitalist empires: Spain, England, and the United States," as stated by Walter Mignolo and Madina Tlostanova (110). The intricate structure of colonial relations translates into the fact that expansionist nations currently detain economic power. In some recent narratives that involve issues of coloniality, the dominant culture's expression of power can be noted as a subtle process of exposition and exploitation - often through the capital that they carry to access the local culture more freely and arbitrarily - mitigated by the enthusiastic visitation and the amazement at folk customs and landscapes. That is the case of Paradise: Love (2012, directed by Ulrich Seidl), a narrative about a middle-aged Austrian woman who travels to Kenya and stays at a resort in front of which a number of young male sex workers wait for potential European clients.

In contemporary times, part of the process of colonial relations lies in the aforementioned Westerner's transit to the territory of the Other, and some of these experiences are either registered or reimagined as fiction in various narratives ${ }^{2}$. The White Masai (2005, directed by Hermine Huntgeburth), for instance, depicts the holiday of a young German woman travelling to Kenya, where she meets and falls in love with a Maasai warrior and ultimately struggles through social conflicts based on cultural differences. Crises of cultural and ethnic identity, as well as issues of power relations between different peoples from distinct geopolitical scenarios, have also been featured in travelling narratives over the years. Such is the case of Black Girl (1966, directed by Ousmane Sembène), which deals with the problems faced by Diouana, a Senegalese woman who moves to France in search of a better life, only to find herself culturally isolated and mistreated while working as a maid for a rich white couple; in Dheepan (2015, directed by Jacques Audiard), Tamil war refugees travel to Paris and try to settle down as the gangstricken neighbourhood where they live becomes a challenge to their adaptation; more recently, I'm no Longer Here (2019, directed by Fernando Frías de la Parra) shows the story of a teenager who flees from gang violence in Monterrey and moves to New York, where the language barrier and cultural discrepancy critically contribute to his exclusion from social circles and eventual return to Mexico. Dilemmas of dislocation are portrayed from various standpoints, including those of the illegal migrant, the war refugee, the expatriate, or the tourist. Film representations of such phenomena have envisioned circumstances in which the subaltern traveller is displaced, excluded, or subjected to psychological or physical trauma. Other narratives are presented through the standpoint of the Western traveller, who fantasises about an untamed and tourism-orientated landscape and interacts with the local culture/s, often reproducing discourses of cultural/national supremacy that constitute new expressions of colonial power. Consequently, some travellers receive the status of immigrants, often depicted as illegal ones, crossing the borders of a global imperialist nationstate and journeying amidst the dangers of capture and even execution lurking 
behind them; whereas others are simple visitors, often the ones who come from Western countries and "move about in relatively unconstrained ways." Clifford also points out the relevance of "reflections on concrete conditions for human connections and alliance cross-cutting class, race, gender, and national locations" - perspectives from which the study of neocolonial relations may take place and scrutinise contemporary expressions of power based on cultural, identity, and/or racial differences (96).

Such differences are delineated by the rapidly growing state of the capitalist mode of production in the twentieth century, and the economic and technological status that contemporary imperial powers enjoy and impose on less powerful nations and cultures. Mignolo and Tlostanova point out that "to conflate differences with values in human beings' hierarchical order is not just to identify 'cultural' differences but to build 'colonial' differences justified in a 'racial' configuration of human being in the planet, their languages and religions, their economies, and their social organizations" (110). To the dominant traveller, native communities play two roles: that of a territory of escapism, where travelling can mean relaxation and exploration of new experiences during a brief break from their routines in their home countries; and that of a safe haven during exceptional times of turmoil, given that such peripheral communities and regions are considered to be inconspicuous - or geopolitically irrelevant - enough to be searched by pursuers. To the peripheral traveller, the movement to a dominant nation means getting closer to the centre and hopefully enjoying the benefits of an imagined quality of life, of financial improvement, of the fulfilment of an image of civility and security that the pressures from economic or political crises - often caused by uneven geopolitical relations to begin with - have disallowed in their home countries.

Modern colonial relations still take into consideration institutionalised exploitation. Whether such relations stem from centre-to-periphery transit - in which travellers from the matrix of colonial power move about and are seen as prioritised individuals who should be served by native workers and in conveniently modified spaces ${ }^{3}$ - or the opposite, - in which mass immigration is reiterated as a danger to the economic and social structures of a dominant country - exploitation takes place on particular levels, being consolidated through relations of difference and assumptions of ethnic, hierarchical prestige. Such are the structures of power that can be observed in the two films chosen for this article. Such films are the 2009 Mexican-American production Sin Nombre, directed by Cary Fukunaga; and the 2006 French-Mexican-American film Babel, directed by Alejandro González Iñárritu.

Having those arguments in mind, the aim of the present investigation is to look at some of such audiovisual narratives that picture dislocation as a source of conflict, oftentimes one that reinforces structures of coloniality. The study will comprise two parts: the first explores the analysis of the illegal immigrant, the image of the uninvited foreigner entering the prosperous and imperialistic nation as seen in Sin Nombre. The second part examines Babel and discusses the image 
of the Western traveller who visits a struggling nation and interacts with the local population; interactions that bring about issues of dominance and cultural disparity. The two investigative sections will deal with thematic and narrative nuances as well as formal characteristics. I will carry out part of the following investigation by making use of film analysis, drawing on some of the scenes from both productions and basing some of the argumentation on filmic elements such as mise-en-scène, editing, cinematography, and screenplay.

The aforementioned areas of cultural conflict can be called contact zones. The term, coined by Mary Louise Pratt (2008), is more concisely described as "social spaces where disparate cultures meet, clash, and grapple with each other, often in highly asymmetrical relations of domination and subordination - such as colonialism and slavery, or their aftermaths as they are lived out across the globe today" (Imperial Eyes 7). Contact zones are a crucial aspect to be observed here because the means for their existence function within the very colonial matrix of power previously discussed by Mignolo and Tlostanova. Territories are shaped as contact zones because of such differences created after historical processes of dominance and exploitation, facilitating nuanced economic and cultural clashes to occur under unbalanced circumstances in contemporary contexts. Such a matrix of power helps enhance the manifestation of imperial discourses, which

are built on the bases of the differences with people, languages, religions, economies, and political organizations of the colonies. In order to exploit, it is necessary to dominate, and in order to dominate, it is necessary to build discourses and belief systems that produce the imperial image as the locus of the right and unavoidable march of history and the colonies as the locus of the erroneous, the inferior, the weak, the barbarians, the primitives, and so on (Mignolo and Tlostanova 110).

Imperialism, in and of itself a form of coloniality still extant, is manifested in different structures of global diplomacy and economic pressure from the mechanisms of late-stage capitalism. Mary Louise Pratt calls attention to the unique structures of imperialist power exercised upon each continent that underwent a process of colonisation in the past, pointing out that, whereas the Americas witnessed a "settler colonialism," - in which lands and natural riches were claimed by imperialist forces as they formed new branches of their own nations -, Africa and India suffered from "administrative colonialism," since already existing sovereignties were gradually taken over while there was little cultural and racial miscegenation, and while a "process of breathlessly expanding productivity and capital accumulation that drove the colonialist scramble [in] Africa" took place ("In the Neocolony" 462-3). However, both forms of imperialism resulted in the creation of systemic boundaries between dominant nations and the colonised world, serving as auxiliary forms of cultural hierarchy and difference, placing both the Latin American and the African subjects in positions of Otherness, figures of cultural appeal, often objectified, seen as peculiar characters of invariable cultural expression. As a result, narratives 
about travel and dislocation have portrayed both forms of journeys - the illegal immigrant and the Western tourist - based on minute elements of prejudice and discrimination that arise, either subtly or explicitly.

\section{Sin Nombre}

Directed by American filmmaker Cary Fukunaga and in international coproduction between the United States and Mexico, Sin Nombre is a result of joint efforts, and said international co-production shows the aspect of globalisation that surrounded the film's making. The film itself works as an artistic contact zone. Focus Features, the production company responsible for distribution, is like the director - from the United States. Mexican actors Gael García Bernal and Diego Luna also helped produce the film; both have had successful acting careers in the United States. Much of the film crew and cast comes from Latin America, but a considerable element of the film's production is also guided by American participants. Therefore, it is important to understand the implications of such details, including the subject matter of the film which Fukunaga decided to closely study by travelling to Mexico, interviewing members of the Mara Salvatrucha and investigating the environment of immigration in Chiapas - something that he discusses in a 2009 interview with Socialist Review. As previously stated, the film is something of a contact zone in its own regard, and the shooting, - which took place in various parts of Mexico City - as well as the international production, operated through cultural contacts and a communication that spread the knowledge of local conflicts and immigration experiences that were ultimately important for such a multicultural work.

Sin Nombre is a film of many conflicts that derive from the same issue: the displacements and social intricacies of illegal immigration. Willy - mainly known for his nom-de-guerre Casper - is a member of the criminal gang Mara Salvatrucha, a brotherhood present in many states of Mexico and the United States. In recruiting a younger fellow named Smiley, Casper gains attention in the film, as the narrative turns to his perspective on life in the brotherhood; a harsh life that tends to be filled with struggles of loyalty and identity that constantly borders tension and physical violence. Smiley is too young and has to prove himself, and so has Casper; and in an early incident, the leader of the gang, Little Mago, kills the latter's girlfriend, awakening a rage in him that escalates into the assassination of said leader. His escape from the Mara Salvatrucha works as a dramatic hook and turns the plotline into a journey of a fugitive towards the United States.

This is the point at which his story converges with that of the Honduran Sayra, herself illegally migrating to the United States with her father and uncle to visit relatives living in New Jersey. She enters the plotline as a contrast in the film's illustrations of life experience: her humble and quiet background clashes against the brutal circumstances of Casper's involvement with the Mara Salvatrucha. Sayra has little notion of what life is in the land of the coloniser, but her father serves as the motivating agent of the American Dream, always referring back to 
the map and telling her how much longer the journey will take, thus turning the immigration issue into a quest and a geographic exploration through the many contact zones to come; a supposedly admirable voyage to pursue prosperity and happiness. However, Sayra becomes the subject of increased violence: she is a female immigrant. Her existence is in constant danger of sexual violence, and the lack of institutionalised protection becomes an expression of violent coloniality through the uneven power structures that constitute the exclusion and illegality in much of Latin American migrations to the U.S. - that forces immigrants to become protectors of their own bodies against sexual violence, capture, and forced sexual work in contexts of already endangered lives ${ }^{4}$. In the turbulent contact zones through which the characters in the film go, Sayra has to employ double the attention and awareness of the constantly dangerous environments around her.

Issues of diaspora can be seen throughout the film. In this article, any instances of the term "diaspora" will follow James Procter's (2007) perspective of the process as "forced and voluntary migrations set in motion by the empire" that originate in the periphery and through which central territories become "home to significant postcolonial settler communities" (151, author's emphasis). In the case of Sin Nombre, that concept is portrayed through images of trains whose rooftops are teeming with people wanting to leave their native lands, imbued with the sense of anticipation and anxiety resulted from the recurrent persecution from the border patrol and the Mexican police itself. And although issues of diaspora oftentimes refer to the Jewish migrations from Palestine and slave trade from Africa during the main period of colonisation in the Americas, contemporary tensions in previously colonised countries and borderlands have repeated the phenomenon. That is the case of cartel violence that has spread across Mexico and compromised local safety in various locations, forcing thousands of individuals to migrate to the U.S. year after year; that is also the case of the waves of Senegalese and Algerian migrations to France after the Second World War - both countries are former French colonies. Either from African countries to Europe or from Latin America to the United States, - as well as in many other contexts - several people have faced the dangers of illegal immigration in order to pursue the often-misleading image of the American way of life as the pinnacle of prosperity and freedom.

It is important to note in which ways power is constructed through the main characters and the narrative motifs that surround them - for example, those of the anticipated romance between Casper and Sayra, and the drama of sacrifice 5 . Casper gets involved with Sayra as both of them are left alone to somehow find their own way past the Texas border. The conflict takes on two facets of danger: that of the border patrol imminent attacks, and that of Casper's escape from the grasp of the Mara Salvatrucha. The threat of death thus comes from both sides of the border: one source of threat acts from a criminal and marginalised modus operandi, whereas the other acts from the position of legal and arbitrary force that is established in the matrix of colonial power. The contact zones gradually fade from Mexican and American cultural and geographic landscapes, but the 
risks remain explicit. Casper considers himself a "dead man", and wants to be left alone in his attempt to flee from the claws of criminal retaliation. Sayra solely wants to seek a better life with him and help him search for new horizons in a new land, away from the dangers of organised crime and death threats. However, that attempt from Casper to stay away from anyone in order to preserve their lives, as well as Sayra's attempt to persuade him to go to the United States with her, mirror two different realities in the film's diegesis: that of the immigrant who wants to forget their ties to their identities and transform into some other cultural and social individual, and that of the immigrant whose marginalised social role is begotten by the inner violence resulted from the maladies of economic injustice. Casper had sought to consolidate his revolt by living in the dangerous universe of a brotherhood situated on the frontier between notions of justice and loyalty and notions of crime and mindless brutality. Both realities - the diasporic mindset driven by economic aspirations and the local offspring of violence - can converge in their most primary principles of survival and coexist in a reality where different motivations can culminate into common goals of migration.

Such instances of identity issues align with the general issues of poverty and life in the developing world to indicate that individuality, ethnicity or even sexuality are under threat of dissolution so that the process of diaspora and search for prosperity can be attained. In the film, the characters are forced to acquire lifedetermining responsibilities and thus live outside of their social realities and ages - they are teenagers undergoing the harsh process of concealing themselves from the sight of mature and vicious authorities and criminal agents - and into a zone that is neutral, ever changing and constantly conflictive: that of the migratory no-man's-land.

The train rooftops are crucial for this point, and become the quick way through which migrants can reach the American "dreamland." Once again, the transformative, risky fast-paced territory can be their best asset of movement an old and easily accessible vehicle that travels across nations - and their worst liability - their visibility becomes critical, and the border patrols easily spot them. The film gradually builds up their image as runaways, others, and transgressors - progressively turning from victims of structural violence and misery in their respective hometowns into strangers in a strange land. In this regard, William E. B. Du Bois (1903) writes of the "double-consciousness, this sense of always looking at one's self through the eyes of others, of measuring one's soul by the tape of a world that looks on in amused contempt and pity" (8, my emphasis). In the critical contact zone of those moving rooftops, stability becomes a hazy afterthought: the confused migrants have little opportunity to communicate and nurture bonds and are always transposing geographical frontiers, but they are also outside of public protective policies and are shunned by other impoverished Latin Americans as even children throw rocks at the passing trains.

After crossing the border and breaching the frontiers of direct violence, Sayra finds herself alone, Casper having died under the violence of drug gangs ${ }^{6}$. This is a point in which the cinematography and mise-en-scène play an important role in 
the construction of dramatic tone. She is depicted as a small figure in the immense urban landscape of a Southern U.S. town (fig. 1), lost amidst the vast territory as the frame pans in a long shot to a composition of huge megastores, car parks, and supermarkets - symbols of American consumerism and exceptionalism. She looks around, constantly aware of danger and of the gaze from the locals, already reaching the state of double-consciousness which is part of the immigrant's reality beyond the border; the awareness of her status as an illegal traveller, having to blend in and build a new individuality. Before that, Casper and Sayra already lived through the conundrum of having to imagine life in the United States as Latin Americans, as members of the American society that have a different ethnic background from the dominant, white individual, and who have to live at the margin, escaping from the mechanisms of immigration law and having to deal with the constant fear of being illegal. The relations of otherness in these contact zones are intensified, as the inequity of opportunities hurts the aspirations of the immigrants, willing to become American citizens and live the "freedom" proposed by the imperialist imagination, but never seen as such. Instead, they are typically seen as outsiders, parasites or agents of degeneration and invasion once their desire to cross the border is discovered.

Sin Nombre emphasises the adversities of the need for the search of a better life vis-à-vis the danger of being found out by the authorities. That emphasis is responsible for establishing and maintaining the suspense in the characters' actions and in the graphical and temporal continuities of the film. With the presentation of almost all the conflicts taking place inside the territories of Mexico, the filmmakers pose a question worth asking: between those who operate in underground illegality, standing in the way of the immigrants, and those who act as local law enforcers, who is the chief antagonist/enemy? Such forces that embody direct and violent threats to the protagonists both result from the oppressive workings of imperialism, but they come from within. The police make sure that nobody gets through the border, or that nobody is allowed to be in the neutral zone of the train rooftops (fig. 2), - the always clandestine and dangerous area - and the gangs and criminal syndicates maintain their arbitrary power on who will live and who will die. The marginalisation of the Other reaches its peak both when Sayra is left without help, having to witness her last hope of a faithful companion and loved one die from the violence existing in her own cultural universe. Threatening forces from within and without function as generators of anxieties and aggression towards the figure of the immigrant.

There is an underlying depiction of the crudity and the annihilation of individuality in the process of illegal immigration of Central Americans into the United States. Film elements work in favour of the dissolution of characters, from their constant lines of sight focussed on the ground ${ }^{7}$ (fig. 3), to extreme close-ups and frantic camera movement, to more slow-paced plan américain shots used to express the moments of critical loss or grief. Both framing and editing work to intensify a sense of foreshadowing, anxiety, despair, and looming danger. Therefore, the film structure emphasises the drama of such a critical context still extant in the 
Americas. As Claire Taylor points out in "Latin America" (2007), "while writers may be the first point of departure in the forging of a postcolonial identity, no less important are the many figures in art, film and popular culture whose works convey a sense of otherness to their publics" (125). In that sense, the film opens up fictional representations of postcolonial others in Central American countries that undergo the imperialistic and economic anxieties and pressures suffered within their own territories from their proximity to such a powerful geopolitical nation-state as the United States, as well as the subsequent issues of immigration and internal violence resulted from marginalisation and economic misery. It also exposes the violent intricacies of these borderlands, the contact zones which function as a territory of tension between the coloniser and the colonised.

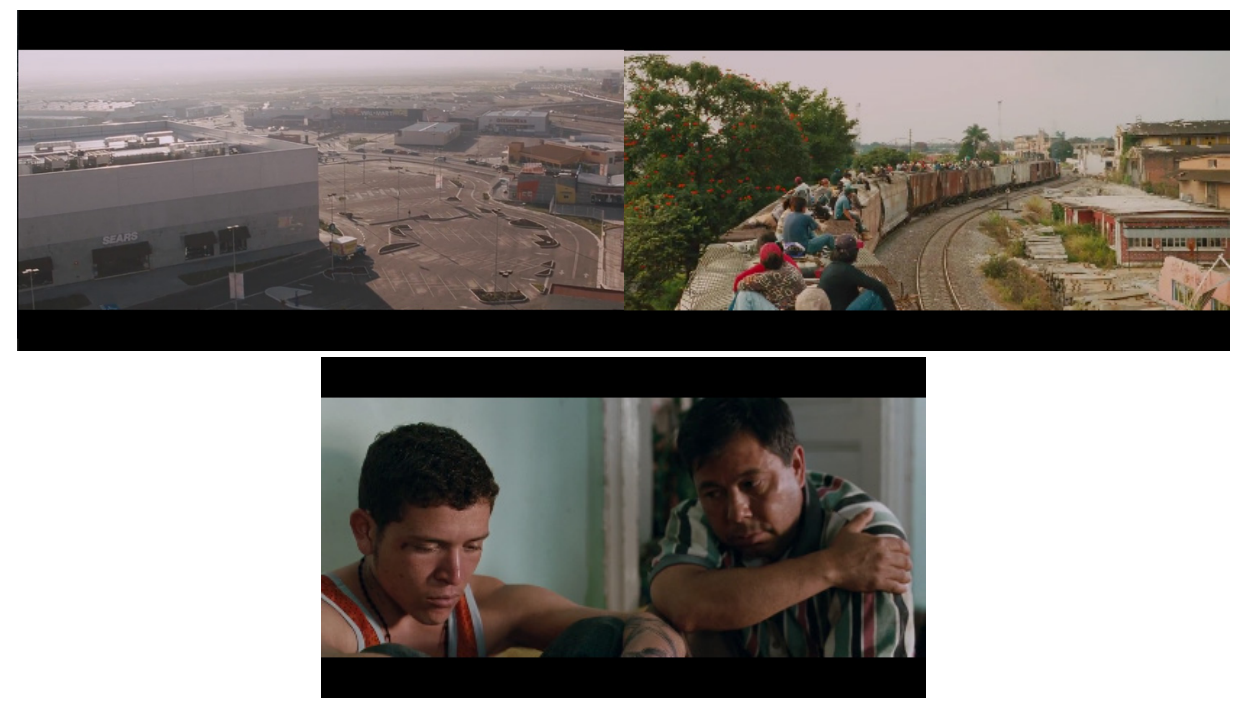

Fig. 1: A long shot of Sears and Wal-Mart megastores and car parks as Sayra walks into U.S. territory. Fig. 2: The train rooftops, areas of transition and danger. Fig. 3: Shots of the constant melancholic countenances in the performance of Sin Nombre.

\section{Babel}

Like Sin Nombre, Babel is an international co-production. And like other acclaimed Mexican filmmakers from recent times such as Alfonso Cuarón and Guillermo del Toro, director Alejandro González Iñárritu has become a relevant name in mainstream cinema and has directed films in American production contexts, including the renowned Birdman (2014) and The Revenant (2015). It could be said that Iñárritu has "travelled" artistically to a U.S.-orientated cinema scenario with his recent projects. By partnering with the giant Paramount Pictures, - through the distribution label Paramount Vantage - as well as other international producers and actors from countries such as Mexico and France, he filmed Babel as a film about communication across borders. Both in production and in its story, the film confirms that premise of internationalisation.

Babel focusses mostly on the Westerner's gaze. It portrays the story of the couple Richard and Susan travelling to Morocco to sort out problems in their 
relationship. Richard and Susan want to stay away from home and work, looking at their trip as a way to repair their troublesome marriage and recover from the pain of losing a child. The narrative intersects with three other stories: a native herder buys a rifle and assigns his two sons to protect the goat herd from jackals; Richard and Susan's children Debby and Mike are at home with their nanny Amelia, whose son is soon to have his wedding back in Mexico; and a young Japanese girl named Chieko Wataya suffers from hearing impairment and lives with her father, a successful businessman. Those stories intertwine and impact each other in a segmented narrative style.

The thematic aspects of Babel expressed through narrative structures are introduced based on the premise of dualities: the realities and perspectives of Susan and Richard; the expectations of Amelia and her son; and the realities of Morocco and the United States. The film starts with a medium shot of an old man walking to a friend's house in the middle of a mountainous landscape that is shown in the background. The initial setting is Morocco, and he is going to sell his neighbour a rifle that will later accidentally shoot an American visitor, Susan, jeopardising the peace of mind of the local farmer's family. The gun was given to him by a Japanese businessman called Yasujiro Wataya, - Chieko's father - who is also a hunter travelling to the country for leisure. The editing of the film tells this story in a non-linear order, alternating between sequences from one place to another. Nevertheless, the focus of this investigation centres on the American couple, who innocuously explore the wonders of the country. Susan does not seem to be happy, and while the crisis in the couple's life together may be the primary source of stress for her, being in a foreign country afflicts her further. She is depicted with a constant countenance of a caution that borders paranoia, and while at an outdoors restaurant (fig. 4), she prevents her husband from having ice in his soda asserting that "we don't know what kind of water is in there" (00:15:58-00:16:03). The apparent paranoia can also be interpreted as cultural mistrust, considering that the rural and distant environment does not inspire safety in an American traveller to whom visiting a foreign country is already a nuisance because of social difference.

Susan repeatedly asserts that she did not want to be there, indicating a shift in the film's construction of suspense that creates anticipation for a conflictive event down the line. She somehow fears for her children back in San Diego. Morocco is then portrayed as a locus of escapism for wealthy tourists, where a simple glance at the unique landscape is a tacit break from the frantic disturbances of the capitalist living style back home, and where the peculiar customs, accents, skin colours, and cuisine temporarily become elements of easy astonishment for imperialist eyes. Richard and Susan find that to be a potential solution, but they give little significance to the subtle constructions of difference that they are nurturing while there. Similar to film crews that travel to remote areas and break the rhythms of life and work in peripheral contexts, Susan and Richard - as well as several other tourists that are caught within the frame with them multiple times throughout the film - change the routines and the usual social structures through the unfamiliar 
interactions of tourism and the transformative purchasing power of Western capital. In the film, "Babel" - as a word that can remind one of linguistic exchange and multiculturalism - becomes an indicator of multicultural communications that are often guided by the ones with historical colonial authority.

After Susan is accidentally shot by Abdullah's son from his farm while the tourists are on a bus that drives down the mountain road, tensions make the differences of coloniality being displayed in those interactions more apparent, especially when one considers the relation between Richard and Anwar, the tour guide. The bus has to retreat to a safer place, as Anwar decides to take them to his nearby hometown where they can telephone the authorities to intervene for Susan's emergency care. As they arrive, Richard starts rushing the locals to do something about the situation, and a disregard for the native social structure comes into play in such a conflict. Richard condescendingly tries to instruct the local physician on how to proceed about the first aid, and also yells at a police officer (fig. 5) when given the news that no ambulance is coming: "this is your fucked-up country! It's your responsibility! You do something!” (01:32:4501:32:47). The close-up shots and the dim lighting intensify the tension of the situation and Richard's infuriated expression that also shows disdain. The scenes expose the unequal relation between the man who disrupts the local order and the public servant who has to show willingness to help an American visitor at all costs. Additionally, when hunting down the possible "terrorists" who had shot the visitor, the authorities take out Abdullah's elder son in a violent and sharp confrontation that demonstrates what can befall those who are not welcoming to Western tourists while in their own land. The regular social order does not hold when an American individual is in those contact zones, seeing as the local - and peripheral - individual is seen with suspicion and scrutinised in spite of his/her - and for the sake of the Westerner's - safety. Such a conflict stems from cultural and ethnic difference based on colonial relations and hierarchisation of lives.

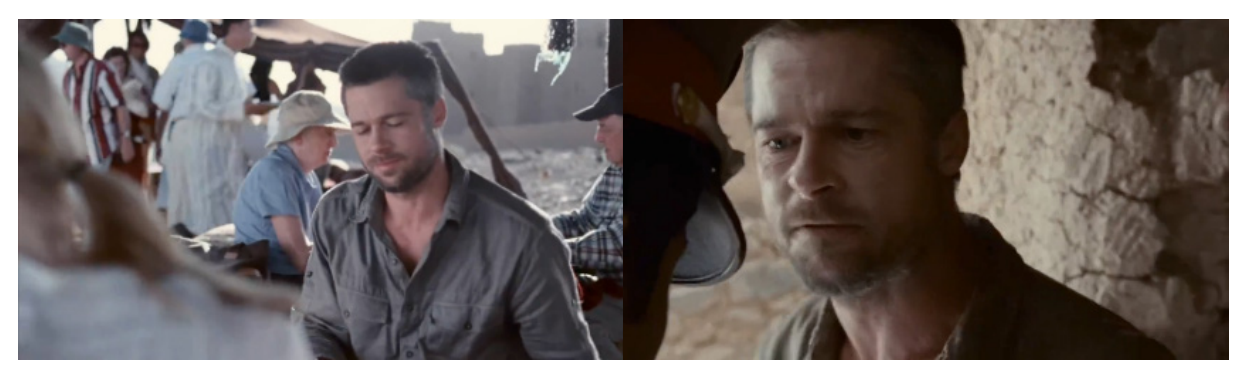

Fig. 4: In a medium shot, Richard and Susan talk at a restaurant, while the low-focus figure of a local is tacitly seen in the background. Fig. 5: Richard violently confronts a police officer in order to get medical assistance for Susan.

Ultimately, relations of power based on contemporary structures of coloniality play a considerable role in narratives about travel and dislocation, as seen in Babel. Mary Louise Pratt (2002) states that:

Modernity's narratives of origin define it with respect to a range of othersfeudalism, absolutism, the primitive (i.e., tribal or subsistence societies), the 
traditional (i.e., peasant and rural societies), the irrational (animals, nonWesterners, and women), and the underdeveloped or backward (the colonial/ neocolonial world). What remains constant is that in every account there has to be an other ("Modernity and Periphery" 25).

Such structures are built on unequal cultural relations and the assumption that technological and economic progress generates civility, and work in similar ways to certain structures of power developed during early colonial periods. In that regard, Mignolo and Tlostanova assert that "'bringing' modernity to the world (in terms of conversion to Christianity, to civilization, to development and market democracy) became a 'mission' that, in the name of progress and development, justified colonization from the conquest of Mexico to the conquest of Iraq" (114). In the late twentieth and early twenty-first centuries - a context in which Babel is set -, modernisation and progress had become parameters for assessing human quality of life, as well as one of the standards under which subaltern nations came to be deemed as the Other and objects of contemporary imperialist discourse. The tourist who brings capital and his/her gaze to the peripheries also acts as a standard of modernisation, investing in the local market and making an economic impact. Richard and Susan take advantage of the local comforts and rest assured that their capital and status as American visitors will grant them free transit and unconditional service.

And yet, economic exploitation is not necessarily a goal of the dominant traveller in Babel as there is no portrayed attempt to appropriate resource, but beliefs and values of cultural contact are built on the premise of modernisation and language, establishing power discrepancies. In other words, the land of the Other is not sufficiently or decently modernised to accommodate Western needs, and the language of the Other is too alien in a globally cultural scenario of relevance to be worth the effort of speaking. Babel does not depict violent measures taken by dominant individuals against the respective subaltern cultures that are portrayed, but the film does illustrate the subtle presence of cultural and class delimitations. Even when the Western characters are fleeing from a state of conflict and desperately trying to stay alive in an African country, they are in the position of being served and feel like the ones to be taken into priority. Since such Western individuals are travelling for tourism in the 2000s, his/her position is of even more favourability. In "Expanding Boundaries: Traveling Theories in the Americas" (2001), Sandra Regina Almeida argues that the traveller is "an agent and trope of modernity, literally and figuratively traversing various boundaries but also participating in creating these same boundaries" (48). Richard disrupts the local order of Anwar's town, forcing the authorities to intervene and send in a helicopter to rescue Susan. Richard reinforces the image of the Moroccan countryside as a site of danger and establishes a boundary for the safety of his wife as a priority, aggressively dismissing the autonomy and contingencies of the local population in that particular, rural contact zone. The fact that the gunshot was caused by an accident becomes part of the background, and the discriminatory paranoia about the dangers of the foreign land are brought to the fore. 
At the same time, Abdullah's sons are found and surrounded in their own land, shot and surrendered; violently submitted by their own law system for accidentally harming an American traveller. Such are the less visible mechanisms of coloniality, whose bases support the inner workings of cultural and racial differences being built for centuries, and that culminate in the contemporary imperialism expressed through progress and capitalism, since the "logic of coloniality has been hidden under the rhetoric of modernity that accompanied the sprouting and growth of Atlantic mercantile or colonial capitalism." (Mignolo and Tlostanova 115). Babel's narrative particularities formulate a commentary on cultural differences in contact zones through images of imperialism that favour the one who is visiting, who is not depicted as the immigrant, but as the modernised tourist. Meanwhile, Amelia tries to reconcile with her occupations and her consideration for her son back in Mexico, crossing the border to attend his wedding. Coming back to the United States after the celebration becomes a turning point, as that contact zone quickly turns into a territory of persecution and violence, since Amelia cannot fulfil all the requirements for return, cannot effectively protect the children of the American couple she works for, being ultimately deported by the border patrol.

Babel highlights how cultural communication and globalisation affect the lives of so many people on different levels. It presents its portrayal of global contact zones, where individuals constantly move through and interact, sometimes triggering impactful events. The editing in the film enhances that effect, often shifting between different perspectives and between different locations, starting different conflictive events that follow a common rhythm in the film's temporal continuity. By constructing a narrative of concurrent perspectives from various spaces, Babel also suggests an aspect of difference, of hierarchy and of power disparity based on race, class, and language.

\section{Final remarks}

The two films explored in this article raise questions about coloniality and relations of power in contact zones, and how such areas of cultural clash can be portrayed in cinematic narratives as loci of colonial difference and conception of boundaries. Sin Nombre is concerned with James Procter's question "Can refugees find a productive alignment within existing diasporic discourses[...]?" (157). Such a question reinforces the importance of acknowledging the existence of a structure of coloniality that affects the lives of diasporic subjects who cross borders through numerous dangers in order to reach a capitalist ideal. Since both Sayra and Casper operate in the systemically violent circumstances of transit that make distinctions between "immigrant" and "refugee" blurry, there is no opportunity for reflection on possible alignments with "existing diasporic discourses" - they simply wish to escape the turmoil of their countries for a supposedly better life. Babel, on the other hand, works within representations of how capitalism has seeped into the economies of poverty-stricken countries 
as the sensible mode of production, since Stuart Hall (1996) states that “'colonisation' signals direct colonial occupation and rule, and the transition to 'post-colonial' is characterised by independence from direct colonial rule, the formation new nation states, forms of economic development dominated by the growth of indigenous capital and their relations of neo-colonial dependency on the developed capitalist world" (248).

Both narratives depict pressures and exclusions based on the ethnic and cultural hierarchy brought about by contemporary coloniality: either from the world of the Latin American who dreams of the capitalist perks, or the privileged tourist from a dominant country who visits a more economically underprivileged country to take advantage of its cultural particularities and resources, leaving an imperialistic model to be followed. Meanwhile, illegal immigrants keep traversing the stormy borders towards an idealised centre; a journey into unknown contact zones and the dangers of authoritative arbitrariness. And, as pointed out by Senthorun Raj (2016), for these "racial minorities," the implementation of antiimmigration measures "has not prevented all forms of immigration. Rather, it has strictly circumscribed their movement through slavery, denials of citizenship, and precarious working permits" (1). Many still remain in the imperial centre, offering their labour, their knowledge, and their bodies to capitalist initiatives in large urban environments. In the case of Sayra, the ideal of dislocation with the prospect of success becomes more significant than a strategy for adaptation and settlement, for awareness of intercultural communication and possible differences. In the case of Susan and Richard, travelling is a potentially pleasant break in their American routine, and the periphery becomes a space of discretion where the exchange is expected to be minimal and necessarily based on their own wishes as imperialistic travellers.

Finally, there is the issue of the border. Whereas Sayra and Casper constantly anticipate the conflictive moment of crossing, Amelia - as an immigrant, but coming from the United States - does not imagine that such a trivial occasion will be so delicately prone to conflict. The border is an imaginary - although substantially influential - locus of violence and colonial displays of power, but also of resistance. It can be a "specific place of hybridity and struggle, policing and transgression," and "sites of regulated and subversive travel, natural and social landscapes" (Clifford 109). The immigrant also changes those landscapes, by traversing them and shaping maps of dissident crossing - moving past several agents of violence and surveillance towards the matrix of colonial power. And through Babel and Sin Nombre one can understand that dislocation takes place in different ways across territories. Both films show the particularities of transit from different perspectives of contemporary colonial structures, as different dynamics of interaction take place, and conflict in contact zones is represented as a consequence of either institutional discrimination or cultural/ethnic inequality. 


\section{Notes}

1. The relevance of imperialism as a modern mechanism of coloniality is expressed through the growth of interventionist and, therefore, neocolonial geopolitics.

2. It is important to note that I will be dealing exclusively with fictional films here.

3. A glaring example of such an urban modification can be noticed in the case of the drastic reformulation in infrastructure that Rio de Janeiro underwent before the 2016 Summer Olympics in order to create an artificial and elitist image of the cityscape for tourists. An article from that year by Donna Bowater for The Telegraph discusses façades that were supposedly built for decoration, but which actually hid much of the sight of favelas located next to busy roads in the city.

4. A 2010 online report by the BBC tells of the challenges faced by migrants from Central America who, in their transit through Mexico, are captured and raped by criminal organisations, and that approximately six out of ten migrant women have gone through experiences of sexual violence, sometimes committed by public officials themselves.

5. Casper ultimately stays behind during a chase scene in which the couple are attempting to cross a river. The young man is soon executed as he distracts the pursuers while Sayra leaves the area.

6. Gangs/brotherhoods and cartels themselves are resulted from and formed due to drug trafficking into U.S. territory, as well as U.S. prohibition laws that directly or indirectly marginalise Latin American people. One example of this is the origin of the infamous Los Zetas cartel back in the 1990s, which was composed of deserted elite soldiers from the Mexican Army who were trained by American forces to combat drug trafficking in an attempt to avoid the flow of narcotics into the United States. Large criminal organisations like Los Zetas are responsible for the state of rapture that many small communities in Mexico - in regions like Sinaloa, Tamaulipas, Nuevo Leon, and many others - find themselves in.

7. Lowered heads are frequent images in the mise-en-scène in Sin Nombre; a way of displaying demeanours of humiliation, subjugation, depression, and hopelessness.

\section{References}

Almeida, Sandra Regina Goulart. "Expanding Boundaries: Traveling Theories in the Americas". Ilha do Desterro, no 40, jan. 2001, pp. 43-59.

Bowater, Donna. "Rio's 'Wall of Shame' between its Ghettos and Shiny Olympic Image". The Telegraph, 23 July 2016, telegraph.co.uk/news/2016/07/23/rios-wallof-shame-between-its-ghettos-and-shiny-olympic-image/

Babel. Directed by Alejandro González Iñárritu. Performances by Brad Pitt, Cate Blanchett, Gael García Bernal, Paramount Vantage, 2006.

Clifford, James. "Traveling Cultures." Cultural Studies, edited by Lawrence Grossberg, Cary Nelson, and Paula Treichler, Routledge, 1992. 96-116.

Du Bois, W. E. B. The Souls of Black Folk. 1903. Edited by Brent Hayes Edwards. New York: Oxford UP, 2007.

Fukunaga, Cary. Interview by Christophe Chataigné. "A Journey on the Railroad." Socialist Review, August 2009, socialistreview.org.uk/338/journey-railroad

Hall, Stuart. "When was the Post-Colonial?" The Postcolonial Question: Common Skies, Divided Horizons, edited by Ian Chambers and Lidia Curtis, Routledge, 1996, pp. 242-260. 
Mignolo, Walter, and Madina Tlostanova. "The Logic of Coloniality and the Limits of Postcoloniality." The Postcolonial and the Global, edited by Revathi Krishnaswamy and John C. Hawley, U of Minnesota P, 2008.

Pratt, Mary Louise. "In the Neocolony: Destiny, Destination, and the Traffic in Meaning." Coloniality at Large: Latin America and the Postcolonial Debates, edited by Mabel Moraña, Enrique Dussel, and Carlos A. Jáuregui, Duke UP, 2008, pp. 459-475.

Imperial Eyes: Travel Writing and Transculturation. Routledge, 2008.

"Modernity and Periphery: Toward a Global and Relational Analysis." Beyond Dichotomies: Histories, Identities, Cultures and the Challenge of Globalization, edited by Elizabeth Mudimbe-Boyi, State U of New York P, 2002, pp. 21-47.

Procter, James. "Diaspora." The Routledge Companion to Postcolonial Studies, edited by John McLeod, Routledge, 2007, pp. 120-28.

Raj, Senthorun. "Immigration, Colonialism, and Globalization." The Wiley Blackwell Encyclopedia of Gender and Sexuality Studies, edited by Nancy A. Naples, John Wiley and Sons, 2016, pp. 1-6.

Sin Nombre. Directed by Cary Joji Fukunaga. Performances by Paulina Gaitán, Edgar Flores, Kristyan Ferrer, Focus Features, 2009.

Taylor, Claire. "Latin America." The Routledge Companion to Postcolonial Studies, edited by John McLeod, Routledge, 2007, pp. 151-57.

Recebido em: 15/07/2020

Aceito em: 20/11/2020 